\title{
Hydroethanolic extract of Juglans regia L. green husks: A source of bioactive phytochemicals
}

\author{
Vanessa Vieira $^{\mathrm{a}, \mathrm{b}, \mathrm{c}}$, Carla Pereira ${ }^{\mathrm{a}}$, Rui M.V. Abreu ${ }^{\mathrm{a}}$, Ricardo C. Calhelha ${ }^{\mathrm{a}}$, Maria José Alves $^{\mathrm{a}}$, \\ João A.P. Coutinho ${ }^{\mathrm{b}}$, Olga Ferreira ${ }^{\mathrm{a}}$, Lillian Barros ${ }^{\mathrm{a}, * *}$, Isabel C.F.R. Ferreira ${ }^{\mathrm{a}, *}$ \\ ${ }^{a}$ Centro de Investigação de Montanha (CIMO), Instituto Politécnico de Bragança, Campus de Santa Apolónia, 5300-253, Bragança, Portugal \\ ${ }^{\mathrm{b}}$ CICECO - Aveiro Institute of Materials, Complexo de Laboratórios Tecnológicos, Aveiro University, Campus Universitário de Santiago, 3810-193, Aveiro, Aveiro, Portugal \\ ${ }^{\mathrm{c}}$ Laboratory of Separation and Reaction Engineering - Laboratory of Catalysis and Materials (LSRE-LCM), Instituto Politécnico de Bragança, Campus de Santa Apolónia, \\ 5300-253, Bragança, Portugal
}

\section{A R T I C L E I N F O}

\section{Keywords:}

Juglans regia L. husks

Phenolic compounds

Naphthalene derivatives

Antioxidant

Anti-inflammatory

Antibacterial

Cytotoxicity

\begin{abstract}
A B S T R A C T
Juglans regia L. (walnut) green husks are an important fraction of waste resulting from the walnut production, thus representing an interesting natural matrix to explore as a source of bioactive compounds. In this work, the hydroethanolic extract of walnut green husks was studied considering the phytochemical composition and the biological activity using different cell model assays, most of them evaluated for the first time for this matrix.

From the HPLC-DAD-ESI/MS ${ }^{\mathrm{n}}$ analysis, sixteen compounds were identified, being the extract mostly composed of naphthalene derivatives (including tetralone derivatives) and less abundant in phenolic compounds (hydroxycinnamic acids and flavonols). The cytotoxic potential of the extract was assessed against tumour (MCF7, NCI-H460, HeLa and HepG2) and non-tumour (PLP2) cell lines. Moreover, the antioxidant activity of the extract was evaluated by inhibition of the oxidative haemolysis (OxHLIA) and the formation of thiobarbituric acid reactive substances (TBARS), and the anti-inflammatory potential by the inhibition of the NO production by the RAW264.7 cell culture. The antibacterial effects of the extract were also evaluated against Gram-negative and Gram-positive bacteria. The results obtained represent a stepping stone for the development of future applications using walnut green husks as a source of added value compounds with bioactive potential.
\end{abstract}

\section{Introduction}

Natural products are recognised sources of bioactive compounds that can find many applications as natural antioxidants, antimicrobial, anti-inflammatory, cytotoxic, and colouring agents, among other functions (Carocho and Ferreira, 2013; Lockowandt et al., 2019; Pinela et al., 2019; Pires et al., 2018; Rostagno and Prado, 2013). Among them, by-products generated in the food and agricultural processing industries can be valorised as natural sources of antioxidants (Balasundram et al., 2006). That is the case of the green husks of walnut trees (Juglans regia L.), a common species in Portugal (Pereira et al., 2007) and the most widespread nut tree in the world (Martínez et al., 2010). They are part of the resulting waste from walnut (fruits) production and their extracts were already proposed as a natural source of dyeing and antimicrobial agents for cosmetic products (Beiki et al., 2018) or the reducing and stabilizing agents in the biosynthesis of gold nanoparticles (Izadiyan et al., 2018). In the food area, walnut green husks were studied as additives with functional properties in meat processing (Salejda et al., 2016) and their extracts were applied to preserve the quality of fresh walnuts during storage (Chatrabnous et al., 2018). Finally, a more traditional application is the use of walnut husks to produce a Slovenian walnut liqueur, which is extremely rich is in phenolic compounds and vitamins (Stampar et al., 2006).

To assist the development of new applications in the food, pharmaceutical, and cosmetic areas, among others, it is important to have a detailed characterization of the phytochemical profile of the extracts and, also, of their bioactivity, as this by-product is a source of molecules of potential pharmaceutical interest (Alshatwi et al., 2012; Bagheri et al., 2012; Jahanban-Esfahlan et al., 2019; Oliveira et al., 2008; Sharma et al., 2013; Soto-Maldonado et al., 2019; Zhou et al., 2015).

A few studies can be found for J. regia L. in which the phytochemical composition of green husks has been determined by HPLC coupled to a UV/DAD detector (Akbari et al., 2012; Chatrabnous et al., 2018; Cosmulescu et al., 2011, 2010; Liu et al., 2008; Soto-Maldonado et al.,

\footnotetext{
* Corresponding author.

** Corresponding author.

E-mail addresses: lillian@ipb.pt (L. Barros), iferreira@ipb.pt (I.C.F.R. Ferreira).
} 
2019; Stampar et al., 2006), reporting the amounts of juglone, phenolic acids, flavonoids and/or tetralone derivatives in the biomass. In another study, phenolic acids and tetralone derivatives were the main compounds identified in samples collected in China, using spectroscopic analysis (UV-Vis, 1H NMR, 13C NMR, 2D NMR, HR-ESI-MS) (Du et al., 2014). Other authors identified phenolic acids and flavonoids during the characterization performed this time by LC-MS (GawlikDziki et al., 2014).

Regarding the bioactivity studies of the walnut green husks, remarkable results regarding its antioxidant activity have been reported, mainly because of their free-radical scavenger and metal chelator capacities (Akbari et al., 2012; Fernández-Agulló et al., 2013; Meshkini and Tahmasbi, 2017). However, only a few of studies (Bagheri et al., 2012; Carvalho et al., 2010; Soto-Maldonado et al., 2019) provided cellular antioxidant activity models which are considered better representatives of the complexity of biological systems (Gupta, 2015). Cellular models have been also used to evaluate the antimicrobial and anti-tumour potentials in previous works (Alshatwi et al., 2012; Carvalho et al., 2010; Fernández-Agulló et al., 2013; Keskin et al., 2012; Oliveira et al., 2008; Sharma et al., 2013; Soto-Maldonado et al., 2019; Zhang et al., 2014).

The present work aims to further characterize the phytochemical composition of Juglans regia L. green husks by liquid chromatography combined with a diode array detector and electrospray ionization mass spectrometer (LC-DAD-ESI/MS ${ }^{\mathrm{n}}$ ), and to extend the study of the bioactive potential of their hydroethanolic extracts using different in vitro cellular approaches. Therefore, the bioactivity of the extract was studied by evaluating the antioxidant (the thiobarbituric acid reactive substances and the oxidative haemolysis inhibition assays), anti-inflammatory (inhibition of the nitric oxide production by macrophages), cytotoxicity (tumour and non-tumour cell lines), and antibacterial (Gram-negative and Gram-positive bacteria) properties. To the best of our knowledge, it is the first time that the selected cell models are applied to evaluate the anti-inflammatory and cytotoxic activities of this extract.

\section{Material and methods}

\subsection{Plant material and extract preparation}

Juglans regia L. green husks were collected in Bragança, Northeast of Portugal, during October of 2018. The samples were dried to a constant weight in an incubator at $35{ }^{\circ} \mathrm{C}$. After, the plant material was ground ( $\approx 40$ mesh), and the homogeneous sample was stored in a desiccator protected from light for subsequent assays.

The extract was obtained by stirring the raw material $(1 \mathrm{~g})$ in an aqueous ethanolic solution $(80 \%$ ethanol, v/v; $30 \mathrm{~mL})$ at room temperature $\left(25^{\circ} \mathrm{C}\right)$ for $60 \mathrm{~min}$. After filtration (Whatman no. 4), the extraction procedure was repeated once. Then, the solvent was recovered in order to obtain a dry extract: first, evaporation at $40{ }^{\circ} \mathrm{C}$ and reduced pressure (rotary evaporator Büchi R-210, Flawil, Switzerland), and then freeze-drying (Telstar Cryodos-80, Terrassa, Barcelona).

\subsection{Phytochemical characterization}

The dry extract was re-suspended at $10 \mathrm{mg} / \mathrm{mL}$ using aqueous ethanol ( $80 \%$ ethanol, $\mathrm{v} / \mathrm{v}$ ) and filtered through a $0.2 \mu \mathrm{m}$ disposable LC filter disk (30 mm, nylon). The phytochemical characterization of walnut green husks was traced by liquid chromatography with diodearray detection (280, 330 and $370 \mathrm{~nm}$ wavelengths) coupled to electrospray mass ionization operating in negative mode (Dionex Ultimate 3000 UPLC and Linear Ion Trap LTQ XL, Thermo Scientific, San Jose, CA, USA) by using a Waters Spherisorb S3 ODS-2 $\mathrm{C}_{18}(3 \mu \mathrm{m}$, $4.6 \mathrm{~mm} \times 150 \mathrm{~mm}$ ), as previously described by the authors (Bessada et al., 2016). The compounds were identified according to their retention time, UV-vis and mass spectra by comparison with those obtained using standard compounds, as well as with literature data. Calibration curves of appropriate standards ( $p$-coumaric acid, $\alpha$-tetralone, juglone and quercetin-3-O-glucoside, HPLC grade, Sigma-Aldrich) were obtained in the range between 200 and $5 \mu \mathrm{g} / \mathrm{mL}$, for the quantitative analysis. The results were expressed as milligrams of each compound per gram of extract $(\mathrm{mg} / \mathrm{g})$. Triplicates were analysed with two independent injections.

\subsection{In vitro antioxidant assays}

The antioxidant activity was evaluated by measuring the thiobarbituric acid reactive substances (TBARS) and by the oxidative haemolysis inhibition (OxHLIA) assays. The extract was diluted at a concentration of $10 \mathrm{mg} / \mathrm{mL}$ (distilled water and PBS solution, respectively, for the TBARS and OxHLIA assays) and then, further dilutions were carried out (500-6.25 $\mu \mathrm{g} / \mathrm{mL})$.

The TBARS assay was performed by measuring the colour intensity of the malondialdehyde-thiobarbituric acid (MDA-TBA) at $532 \mathrm{~nm}$, following a methodology described by Barreira et al. (2013), and the results were expressed as $\mathrm{IC}_{50}$ values (sample concentration providing $50 \%$ of antioxidant activity).

The OxHLIA assay was carried out by evaluating the delay effect of the extract on the erythrocyte haemolysis at $690 \mathrm{~nm}$, as previously described by Lockowandt et al. (2019). The results were presented as $\mathrm{IC}_{50}$ values (extract concentration that delayed the haemolysis time for $60 \mathrm{~min}$, with $50 \%$ of intact erythrocytes). Trolox was used as positive control for both antioxidant activity evaluations. Triplicates were used and three independent assays were performed.

\subsection{Anti-inflammatory activity}

The walnut green husks extract was re-suspended in water at a concentration of $10 \mathrm{mg} / \mathrm{mL}$ and then diluted in the range between 500 and $7.8 \mu \mathrm{g} / \mathrm{mL}$. To perform the assay, the nitric oxide production by a mouse macrophage-like cell line (RAW264.7) was measured, using the Griess Reagent System (GRS) kit. The inhibition of the NO production was performed according to the methodology described by Corrêa et al. (2015), with measurements at $515 \mathrm{~nm}$ (EL $x 800$ microplate reader, BioTek Instruments, Inc., Winooski, VT, USA). Results were expressed as $\mathrm{EC}_{50}$ values (sample concentration providing $50 \%$ of inhibition of NO production) and dexamethasone was used as a positive control, while for the negative control, no lipopolysaccharide (LPS) was added. For the assay, triplicates were used in three independent assays.

\subsection{Cytotoxicity assays}

The hydroethanolic extract of walnut green husks was re-suspended in water at $10 \mathrm{mg} / \mathrm{mL}$ and, then, further diluted in the range between 500 and $7.8 \mu \mathrm{g} / \mathrm{mL}$. The cytotoxic properties were assessed using four human tumour cell lines: MCF-7 (breast adenocarcinoma), NCI-H460 (non-small cell lung cancer), HeLa (cervical carcinoma), and HepG2 (hepatocellular carcinoma). A non-tumour cell line (porcine liver primary cells, PLP2) was also evaluated using a procedure described by Abreu et al. (2011). The sulforhodamine B assay was performed according to a protocol described elsewhere (Barros et al., 2013). Ellipticine was used as a positive control, while the negative control was represented by each suspension of cells. The results were expressed in $\mathrm{GI}_{50}$ values (concentration that inhibited $50 \%$ of the cell proliferation). Three independent assays were performed using triplicates.

\subsection{Antibacterial activity}

The hydroethanolic extract of walnut green husks was dissolved in a mixture of dimethyl sulfoxide (DMSO) + Mueller-Hinton Broth (MHB)/ Tryptic Soy Broth (TSB) $(5+95 \%$, v/v) to give a final concentration of $100 \mathrm{mg} / \mathrm{mL}$ for the stock solution and, then, successive dilutions were 
carried out ranging from 20 to $1.25 \mathrm{mg} / \mathrm{mL}$. The antimicrobial potential was assessed using five Gram-negative bacteria (Escherichia coli, Proteus mirabilis, Klebsiella pneumoniae, Pseudomonas aeruginosa and Morganella morganii) and three Gram-positive bacteria (Enterococcus faecalis, Listeria monocytogenes and methicillin-resistant Staphylococcus aureus MRSA). These strains were clinical isolates donated by hospitalized patients (Local Health Unit of Bragança and Hospital Centre of Trás-osMontes and Alto-Douro, Vila Real, Northeast of Portugal) with multiresistant profile, previously characterized by Alves et al. (2014). For each bacteria, the minimum inhibitory concentration (MIC) and minimum bactericidal concentration (MBC) were determined using a colorimetric assay as described by Kuete et al. (2011) and Pires et al. (2018). Duplicates were used and three independent assays were performed.

\section{Results and discussion}

\subsection{Phytochemical composition of walnut husks}

The phytochemical composition of the hydroethanolic extracts of $J$. regia green husks was characterized for samples at the mature stage of the fruit (October 2018) and the main molecules identified are presented in Table 1 with their quantification. The tentative identification was carried out according to their retention time (Rt), maximum absorbance wavelength $\left(\lambda_{\max }\right)$, pseudomolecular ion $\left([\mathrm{M}-\mathrm{H}]^{-}\right)$, the correspondent fragmentation pattern $\left(\mathrm{MS}^{2}\right)$, and also using literature information. It was possible to identify sixteen compounds as presented in Fig. 1.

The extract was composed of three organic acids, of which two phenolic acids ( $p$-hydroxycinnamic acid derivatives), six tetralone derivatives, three naphthalene derivatives, and four flavonoids (flavonols).

The first compound presented a fragment at $m / z 133\left([\mathrm{M}-\mathrm{H}]^{-}\right)$and maximum UV absorption at $212 \mathrm{~nm}$, and additional $\mathrm{MS}^{2}$ fragments at $\mathrm{m} / \mathrm{z} 115,89$ and 71 ; therefore, compound 1 was tentatively identified as malic acid. The presence of this organic acid in Juglans spp., as well as the MS/MS fragmentation pattern, was previously reported by Wang et al. (2017) in J. mandshurica Maxim. branches.

The two phenolic acids identified in $J$. regia green husks, peaks 2 and $6\left([\mathrm{M}-\mathrm{H}]^{-}\right.$at $\left.m / z 337\right)$, were assigned as 3- and 4-p-coumaroylquinic acid, respectively. The $\mathrm{MS}^{2}$ fragments at $m / z 191,173,163$, 155 and 119 are in accordance to the hierarchical fragmentation pattern described by Clifford et al. (2003), with base peak at $m / z 163$ for the 3-p-coumaroylquinic acid and $m / z 173$ for the 4-p-coumaroylquinic acid. These assumptions were also in agreement with the observations of Gawlik-Dziki et al. (2014) using the same plant material, reporting similar mass fragmentations and maximum UV-Vis absorption (307 and $310 \mathrm{~nm}$, respectively). The amounts of both hydroxycinnamic acids were very similar $(1.07 \quad \pm \quad 0.03 \mathrm{mg} / \mathrm{g}$ dry extract and $1.356 \pm 0.001 \mathrm{mg} / \mathrm{g}$ dry extract, for 3-p-coumaroylquinic and 4-pcoumaroylquinic acids, respectively), yielding a total amount of phenolic acids of $2.42 \pm 0.03 \mathrm{mg} / \mathrm{g}$ dry extract.

Peaks 11 and $12\left([\mathrm{M}-\mathrm{H}]^{-}\right.$at $\left.m / z 463\right), 14\left(\left[\mathrm{M}-\mathrm{H}^{-}\right.\right.$at $\left.\mathrm{m} / \mathrm{z} 433\right)$ and $15\left([\mathrm{M}-\mathrm{H}]^{-}\right.$at $\left.m / z 447\right)$ yielded the same base peak at $m / z 301$. These compounds were identified as quercetin glycoside derivatives, more precisely: quercetin-3-O-glucoside (11), quercetin-O-hexoside (12), quercetin- $O$-pentoside (14) and quercetin- $O$-deoxyhexoside (15). The presence of these flavonols are in agreement with the results reported by Gawlik-Dziki et al. (2014), as well as the mass fragments and UV-vis maximum absorptions for the same plant material. Regarding the amounts found for the quercetin derivatives, they ranged from $0.265 \pm 0.005 \mathrm{mg} / \mathrm{g}$ dry extract for the $O$-hexoside form to $0.3822 \pm 0.0003 \mathrm{mg} / \mathrm{g}$ dry extract for the $O$-pentoside one, yielding a total amount of flavonoids of $1.293 \pm 0.004 \mathrm{mg} / \mathrm{g}$ dry extract. These compounds were the least abundant class of molecules found.

The following group of compounds, tetralone derivatives, are

Table 1

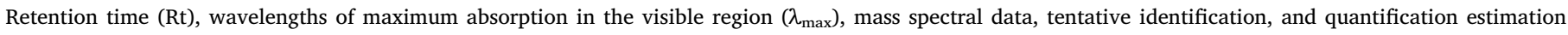
(mean $\pm \mathrm{SD}, \mathrm{n}=6$ ) of the tentatively identified compounds in green husks extracts of $J$. regia.

\begin{tabular}{|c|c|c|c|c|c|c|}
\hline Peak & $R t$ (min) & $\lambda_{\max }(\mathrm{nm})$ & $\begin{array}{l}{[\mathrm{M}-\mathrm{H}]^{-}(\mathrm{m} /} \\
z)\end{array}$ & $\operatorname{MS}^{2}(m / z)$ & Tentative identification & Walnut green husks (mg/g extract) \\
\hline 1 & 5.2 & 212 & 133 & 115(100), 89(10), 71(8) & Malic acid ${ }^{\mathrm{a}}$ & n.q. \\
\hline 2 & 6.0 & 307 & 337 & $\begin{array}{l}\text { 191(10), 173(10), 163(100), 155(5), } \\
\text { 119(7) }\end{array}$ & 3-p-Coumaroylquinic acid ${ }^{\mathrm{b}}$ & $1.07 \pm 0.03$ \\
\hline 3 & 7.7 & 262,320 & 339 & $159(100), 115(52)$ & Dihydroxytetralone hexoside $\mathrm{e}^{\mathrm{a}, \mathrm{c}}$ & $0.42 \pm 0.02$ \\
\hline 4 & 8.4 & 222,263 & 409 & $\begin{array}{l}337(28), 247(100), 203(77), 175(84) \text {, } \\
131(5)\end{array}$ & Trihydroxynaphthalene hexoside derivative ${ }^{c}$ & $4.2 \pm 0.2$ \\
\hline 5 & 10.9 & 263,320 & 177 & 159(100), 131(15), 115(5) & Dihydroxytetralone $\mathrm{a}^{\mathrm{a}, \mathrm{c}}$ & $7.1 \pm 0.4$ \\
\hline 6 & 11.9 & 310 & 337 & 191(5), 173(100), 163(5), 119(3) & 4-p-Coumaroylquinic acid ${ }^{\mathrm{b}}$ & $1.356 \pm 0.001$ \\
\hline 7 & 13.0 & 223,264 & 193 & $175(100), 157(5), 147(3), 131(3)$ & Trihydroxytetralone $\mathrm{a}^{\mathrm{a}, \mathrm{c}}$ & $1.174 \pm 0.005$ \\
\hline 8 & 15.7 & 260,320 & 491 & 331(92), 271(100), 211(100), 169(10) & Dihydroxytetralone galloyl-hexoside isomer $1^{\mathrm{a}, \mathrm{c}}$ & $2.8 \pm 0.1$ \\
\hline 9 & 16.6 & 220,264 & 491 & $331(94), 271(100), 211(5), 169(3)$ & Dihydroxytetralone galloyl-hexoside isomer $2^{\mathrm{a}, \mathrm{c}}$ & $1.486 \pm 0.003$ \\
\hline 10 & 17.7 & $\begin{array}{l}213,261 \\
330\end{array}$ & 507 & $331(100), 271(42), 211(5), 169(3)$ & Trihydroxytetralone galloyl-hexoside ${ }^{\mathrm{a}}$ & $1.23 \pm 0.04$ \\
\hline 11 & 18.5 & 350 & 463 & $301(100)$ & Quercetin 3-O-glucoside $^{\mathrm{d}}$ & $0.3255 \pm 0.0003$ \\
\hline 12 & 18.8 & 348 & 463 & $301(100)$ & Quercetin $O$-hexoside ${ }^{\mathrm{d}}$ & $0.265 \pm 0.005$ \\
\hline 13 & 20.3 & 222,273 & 489 & $\begin{array}{l}313(61), 301(56), 271(100), 211(15), \\
169(8)\end{array}$ & Trihydroxynaphthalene galloyl-hexoside ${ }^{c}$ & $4.7 \pm 0.3$ \\
\hline 14 & 21.4 & 350 & 433 & $301(100)$ & Quercetin $O$-pentoside ${ }^{\mathrm{d}}$ & $0.3822 \pm 0.0003$ \\
\hline 15 & 22.4 & 350 & 447 & $301(100)$ & Quercetin $O$-deoxyhexoside $\mathrm{f}^{\mathrm{f}}$ & $0.321 \pm 0.001$ \\
\hline \multirow[t]{6}{*}{16} & 26.2 & 223,263 & 487 & $325(100), 307(10)$ & Jugnaphthalenoside $A^{c}$ & $0.76 \pm 0.02$ \\
\hline & & & & Total phenolic acids & $2.42 \pm 0.03$ & \\
\hline & & & & Total flavonoids & $1.293 \pm 0.004$ & \\
\hline & & & & Total phenolic compounds & $3.72 \pm 0.03$ & \\
\hline & & & & Total tetralone derivatives & $14.2 \pm 0.2$ & \\
\hline & & & & Total naphthalene derivatives & $9.68 \pm 0.04$ & \\
\hline
\end{tabular}

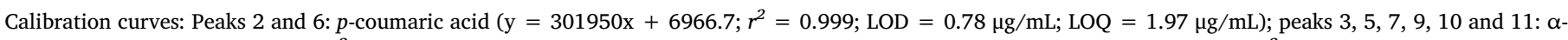

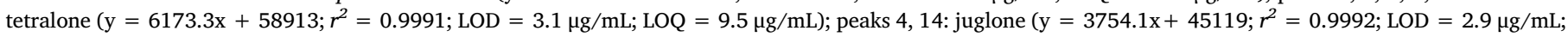

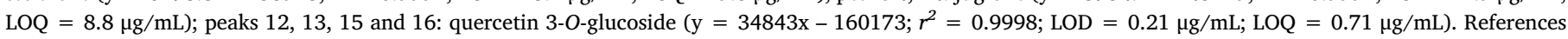

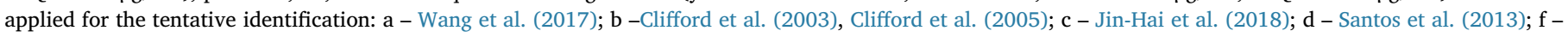
Gawlik-Dziki et al. (2014). n.q.: not quantified. 

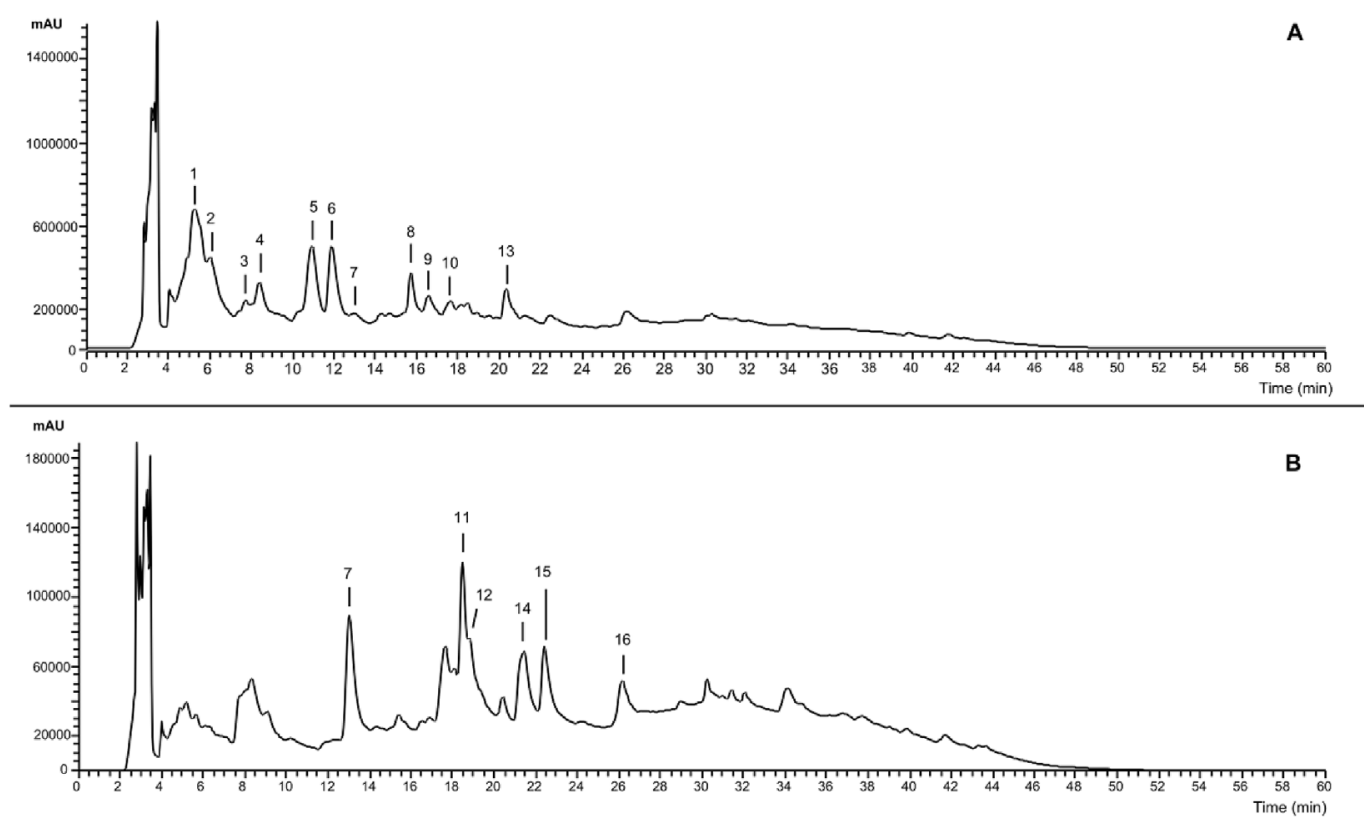

Fig. 1. HPLC phytochemical profile of J. regia L. green husks at $280 \mathrm{~nm}$ (A) and $370 \mathrm{~nm}$ (B) wavelengths. The peaks identification and quantification are presented in Table 1.

widely distributed in Juglans spp. plant material (e.g. pericarps, green husks, stem-bark, branches, etc.) (Du et al., 2014; Li et al., 2013, 2008a; Liu et al., 2010; Talapatra et al., 1988; Wang et al., 2017). Particularly, the tetralone derivatives found in green husks of $J$. regia usually occur as hydroxyl, hexosyl and hydroxybenzoyl derivatives, with several isomeric alternatives (Zhou et al., 2015). In this work, peak $3\left([\mathrm{M}-\mathrm{H}]^{-}\right.$ at $m / z 339)$, peak $5\left([\mathrm{M}-\mathrm{H}]^{-}\right.$at $\left.m / z 177\right)$ and peak $7\left([\mathrm{M}-\mathrm{H}]^{-}\right.$at $m / z$ 193) were identified as dihydroxytetralone hexoside, dihydroxytetralone and trihydroxytetralone, respectively. These identifications were possible by comparison with literature data, describing the different fragmentation patterns of individual compounds found in $J$. mandshurica samples (Jin-Hai et al., 2018; Wang et al., 2017). Peaks 8 and $9\left([\mathrm{M}-\mathrm{H}]^{-}\right.$at $\left.m / z 491\right)$, and peak $10\left([\mathrm{M}-\mathrm{H}]^{-}\right.$at $\left.m / z 507\right)$ showed similar MS ${ }^{2}$ fragments at $m / z 271,211$ and 169. Following the observations of Jin-Hai et al. (2018) and Wang et al. (2017), the compounds were identified as tetralone galloyl hexoside derivatives, specifically, dihydroxytetralone galloyl hexoside isomers (peaks 8 and 9) and trihydroxytetralone galloyl hexoside (peak 10). Dihydroxytetralone was the most abundant compound (7.1 $\pm 0.4 \mathrm{mg} / \mathrm{g}$ dry extract), about half of the total amount of tetralone derivatives $(14.2 \pm 0.2 \mathrm{mg} / \mathrm{g}$ dry extract). Dihydroxytetralone galloyl-hexoside isomers were the second most abundant compounds $(2.8 \pm 0.1 \mathrm{mg} / \mathrm{g}$ dry extract and $1.486 \pm 0.003 \mathrm{mg} / \mathrm{g}$ dry extract, for isomers 1 and 2 , respectively), and dihydroxytetralone hexoside was the least abundant tetralone derivative $(0.42 \pm 0.02 \mathrm{mg} / \mathrm{g}$ dry extract $)$.

Peaks 4, 13 and 16 correspond to naphthalene derivatives. This group of molecules was already identified in $J$. mandshurica fruits (JinHai et al., 2018), husks (Jin-Hai et al., 2018; Zhou et al., 2015) and branches (Wang et al., 2017). As with tetralone derivatives, natural naphthalene also occurs with hydroxyl, hexosyl and hydroxybenzoyl substitutions (Sun et al., 2012). Peak $4\left([\mathrm{M}-\mathrm{H}]^{-}\right.$at $m / z$ 409) was identified due to its $\mathrm{MS}^{2}$ fragments, which complies with the previous fragmentation pattern descriptions of Jin-Hai et al. (2018) and Wang et al. (2017) for a trihydroxynaphthalene hexoside; thus, the loss of $-72 \mathrm{u}$ was unknown and, therefore, peak 4 was assigned to a trihydroxynaphthalene hexoside derivative. Peak $13\left([\mathrm{M}-\mathrm{H}]^{-}\right.$at $\left.\mathrm{m} / \mathrm{z} 489\right)$ was identified as trihydroxynaphthalene galloyl-hexoside, while peak $16\left([\mathrm{M}-\mathrm{H}]^{-}\right.$at $\left.\mathrm{m} / \mathrm{z} 487\right)$ was identified as jugnaphthalenoside A, taking into account the fragmentation patterns reported by Jin-Hai et al. (2018). Regarding their quantification, these molecules were present in similar amounts $(4.2 \pm 0.2 \mathrm{mg} / \mathrm{g}$ dry extract and $4.7 \pm 0.3 \mathrm{mg} / \mathrm{g}$ dry extract, respectively), values that are considerably higher than the yield obtained for jugnaphthalenoside A $(0.76 \pm 0.02 \mathrm{mg} / \mathrm{g}$ dry extract). Naphthalene derivatives were the second most abundant group of compounds.

The phytochemical profile of Juglans regia green husks is quite variable; however, our findings are in good agreement with the most abundant groups of compounds found in literature for Juglans spp. samples such as phenolic acids and flavonoids (Cosmulescu et al., 2010; Gawlik-Dziki et al., 2014; Stampar et al., 2006), as well as tetralone and naphthalene derivatives (Du et al., 2014; Jin-Hai et al., 2018; Wang et al., 2017). As phenolic compounds (e.g. phenolic acids and flavonols) are widely distributed throughout the plant kingdom (Crozier et al., 2006), their presence in walnut green husks was expected. However, their lower abundancy compared to other compounds such as tetralones and naphthalene derivatives in walnut green husks is little discussed in the literature. In fact, this type of comparisons were only carried out for the presence of another naphthalene derivative, juglone (naphthoquinone), being the most abundant molecule in walnut green husks previously studied by Cosmulescu et al. (2010) and Stampar et al. (2006), but not in walnut leaves (Cosmulescu et al., 2014a, 2014b). However, in the present work, juglone was not detected in walnut green husks samples.

The bioactive potential of this extract was further evaluated, aiming to complement the phytochemical characterization, and support its potential application in several areas including food, cosmetic and pharmaceutical industries (Balasundram et al., 2006; Butler et al., 2014; Newman and Cragg, 2016).

\subsection{Bioactivity of the hydroethanolic extracts}

The antioxidant activity of the extracts was evaluated by two in vitro assays using cells and tissues. The extract potential for the inhibition of the lipid peroxidation (evaluated by the thiobarbituric acid reactive substances - TBARS assay) was assessed using porcine brain tissues, while the maintenance of the erythrocyte integrity by the extract action was performed by the oxidative haemolysis inhibition (OxHLIA) assay. The results are presented in Table 2, and the anti-haemolytic action of the extracts is presented in Fig. 2.

The mean concentration leading to half of the malondialdehyde 
Table 2

Antioxidant activity, NO formation inhibition and cytotoxicity of $J$. regia green husks (mean $\pm \mathrm{SD}, \mathrm{n}=9$ ).

\begin{tabular}{|c|c|c|}
\hline & Hydroethanolic extract & Positive control \\
\hline \multicolumn{3}{|c|}{ Antioxidant activity $\left(E C_{50}\right.$ values, $\left.\mu \mathrm{g} / \mathrm{mL}\right)$} \\
\hline TBARS inhibition & $101 \pm 4$ & $5.8 \pm 0.6$ \\
\hline OxHLIA & $80 \pm 4$ & $19.6 \pm 0.6$ \\
\hline \multicolumn{3}{|c|}{ Anti-inflammatory activity $\left(E C_{50}\right.$ values, $\mu \mathrm{g} / \mathrm{mL}$ ) } \\
\hline Nitric oxide (NO) production & $56 \pm 3$ & $16 \pm 1$ \\
\hline \multicolumn{3}{|l|}{ Cytotoxicity $\left(G I_{50}\right.$ values, $\left.\mu \mathrm{g} / \mathrm{mL}\right)$} \\
\hline MCF-7 (breast carcinoma) & $26 \pm 1$ & $1.21 \pm 0.02$ \\
\hline NCI-H460 (non-small lung cancer) & $41 \pm 2$ & $0.9 \pm 0.1$ \\
\hline HeLa (cervical carcinoma) & $34 \pm 2$ & $1.03 \pm 0.09$ \\
\hline HepG2 (hepatocellular carcinoma) & $24 \pm 2$ & $1.1 \pm 0.09$ \\
\hline PLP2 (porcine liver primary cells) & $87 \pm 4$ & $2.3 \pm 0.2$ \\
\hline
\end{tabular}

Trolox was used as positive control in the antioxidant activity assays, dexamethasone in the anti-inflammatory activity assay, while ellipticine was used in the cytotoxicity assays.

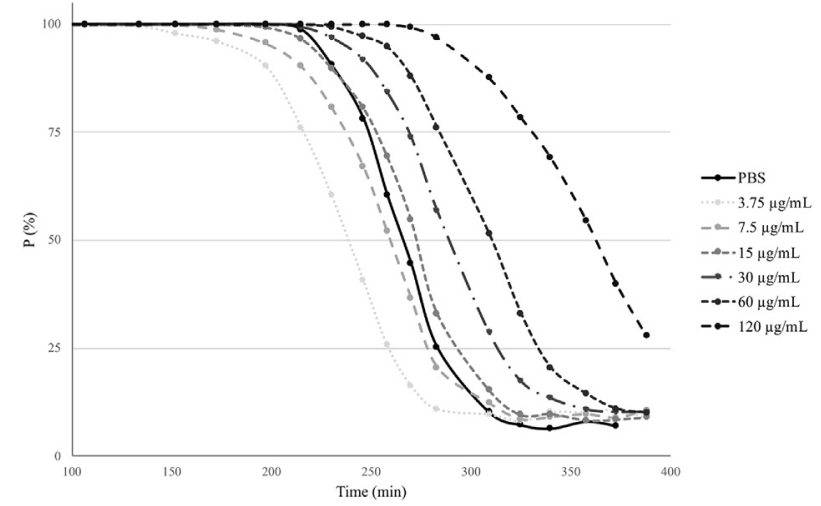

Fig. 2. Kinetic behaviour of $J$. regia green husks extract during the erythrocyte heamolysis (OxHLIA assay).

formed during the peroxidation of the unsaturated fatty acids present in the brain tissues, in the TBARS assay, was $\mathrm{IC}_{50}=101 \pm 4 \mu \mathrm{g} / \mathrm{mL}$. In the OxHLIA assay, the inhibition of the erythrocyte's membrane damage promoted by the free radical AAPH was achieved at $\mathrm{IC}_{50}=80 \pm 4 \mu \mathrm{g}$ / $\mathrm{mL}$. The $\mathrm{IC}_{50}$ values obtained by the OxHLIA assay were lower than the ones for the TBARS, contrarily to the results found for the positive control, with $\mathrm{IC}_{50}=19 \pm 0.6 \mu \mathrm{g} / \mathrm{mL}$ and $5.8 \pm 0.6 \mu \mathrm{g} / \mathrm{mL}$, respectively.

To our knowledge, the effect of the walnut green husks extract against the lipid oxidation through the TBARS assay was only reported by Bagheri et al. (2012). The hydroalcoholic walnut green husk extract was able to inhibit the LDL oxidation with a dose-dependency from 0.2 to $20 \mu \mathrm{g} / \mathrm{mL}$. Regarding the anti-haemolytic potential, Carvalho et al. (2010) also evaluated the dose-dependency between different concentrations of the methanolic extract and the time of the AAPH free radical exposure. The $\mathrm{IC}_{50}$ mean value was $127 \pm 14 \mu \mathrm{g} / \mathrm{mL}$ after $3 \mathrm{~h}$ of reaction ( $\Delta t \approx 60 \mathrm{~min}$ ), which is in agreement with the results obtained in this work.

The anti-inflammatory potential was assessed using macrophages cells (Table 2). After recognition of a pathogen, macrophages release a series of toxic molecules as an immune defence, being one of them nitric oxide (NO). In this context, NO is a recognised intercellular marker in the immune system, being involved in immunologically mediated diseases and inflammation (Tripathi et al., 2007). An extract concentration of $56 \pm 3 \mu \mathrm{g} / \mathrm{mL}$ inhibited half of the NO produced by the macrophage's cultures $\left(\mathrm{EC}_{50}\right)$. This result was 3.5 -fold higher than the pure standard used for the positive control, dexamethasone, with $\mathrm{EC}_{50}=16 \pm 1 \mu \mathrm{g} / \mathrm{mL}$. To the best of our knowledge, this assay was applied for the first time to the extracts of walnut husks. The inhibition of the NO production is frequently carried out by simple chemical reactions using sodium nitroprusside, but in those cases only the antioxidant activity is evaluated (Akbari et al., 2012; Fernández-Agulló et al., 2013; Ghasemi et al., 2011; Sharma et al., 2013). It is usually applied as an antiradical indicator because the source of NO is not provided by cells (e.g. macrophages). In this context, some studies about the NO scavenging activity of walnut green husks can be found. Akbari et al. (2012) showed that the methanolic extracts of six green husks genotypes were able to capture, on average, about $69.18 \pm 1.57 \%$ of the NO free radicals. The results for the NO inhibition in sample extracts from India (obtained with different organic solvents) were all $>500 \mu \mathrm{g} / \mathrm{mL}$ (Sharma et al., 2013). Ghasemi et al. (2011) obtained $\mathrm{IC}_{50}$ values ranging from 141 to $2890 \mu \mathrm{g} / \mathrm{mL}$ for methanolic extracts depending on the $J$. regia cultivar. Regarding the NO scavenging activity of other samples from Portuguese origin, the aqueous extract of a Mellanaise walnut husk variety resulted in $\mathrm{EC}_{50}$ values of $960 \pm 130 \mu \mathrm{g} / \mathrm{mL}$ (Fernández-Agulló et al., 2013). Though the results cannot be directly compared, as they were obtained in different assays, the concentration values from the chemical assay were all higher than the ones obtained in this study with the cellular model.

Beyond the intrinsic characteristics of the plant material (geographic location, time of collection), the differences found in literature are also due to the selected extraction conditions (extraction technique, solvent, time), which are selective factors during the extraction of compounds from natural matrices (Sampaio et al., 2016; Zhang et al., 2018).

Regarding the cytotoxicity of walnut green husks, the results for the tumour and non-tumour cell cultures are presented in Table 2. The extract showed similar activity against the four tumour cell lines (nonsmall lung cancer, breast, cervical and hepatocellular carcinomas), with lower $\mathrm{GI}_{50}$ values (higher cytotoxic potential) against the HepG2 (hepatocellular carcinoma) and MCF-7 (breast carcinoma) cells, reaching $24 \pm 2 \mu \mathrm{g} / \mathrm{mL}$ and $26 \pm 1 \mu \mathrm{g} / \mathrm{mL}$, respectively. Slightly lower activity was obtained against HeLa (cervical carcinoma) and NCI-H460 (non-small lung cancer) cell lines, with $\mathrm{GI}_{50}$ values of $34 \pm 2 \mu \mathrm{g} / \mathrm{mL}$ and $41 \pm 2 \mu \mathrm{g} / \mathrm{mL}$, respectively. Concerning the results of the hepatotoxicity, the extract was toxic for the primary liver cells; however, at higher concentrations compared to the tumour cell lines, with $\mathrm{GI}_{50}=87 \pm 4 \mu \mathrm{g} / \mathrm{mL}$.

To the best of our knowledge, it is the first time that the cytotoxic potential of $J$. regia green husks extracts is studied against the proliferation of the selected cell cultures. Nevertheless, the cytotoxic effect of pure isolated compounds from Juglans mandshurica Maxim extracts was evaluated for HepG2 cells (Yang et al., 2019; Zhou et al., 2015). According to Zhou et al. (2015), lower IC $_{50}$ values were found for naphthoquinone derivatives than the ones obtained for tetralone, and the non-glycosylated forms were more active against the HepG2 cells than the glycosylated ones: dihydroxynaphthoquinone isomers $(7.33 \pm 0.52 \mu \mathrm{M}$ to $15.37 \pm 1.63 \mu \mathrm{M})<$ dihydroxy tetralone (regiolone: $56.87 \pm 4.27 \mu \mathrm{M})<$ trihydroxy naphthoquinone hexoside isomers $(78.61 \pm 2.38 \mu \mathrm{M}$ to $83.32 \pm 4.54 \mu \mathrm{M})$, while dihydroxyand trihydroxytetralone hexoside isomers were not active against the cell culture. Similar results were found for regiolone in Juglans cathayensis Dode samples against the same cell line $(42.56 \mu \mathrm{M})$ ( $\mathrm{Li}$ et al., 2008b). The authors also presented results about the regiolone toxicity against HeLa $(30.48 \mu \mathrm{M})$ and HL-60 $(40.21 \mu \mathrm{M})$ cell cultures. Furthermore, two tetralone dimers (juglanone A and B) were isolated from $J$. regia pericarps (husks) by Li et al. (2013). The cytotoxicity of the pure compounds was assessed against a series of human cell lines (A549, MCF-7, BEL-7402, HeLa, COLO205, BGC-823, and SK-OV-3). Juglanone A showed a higher inhibition rate for the MCF-7 cells ( $94.16 \pm 0.37 \%$ ), while juglanone B revealed higher activity against HeLa cells $(92.62 \pm 2.00 \%)$. Also, the five cyclic diarylheptanoids isolated by Yang et al. (2019) from the ethanolic (95\%) extract resulted in $\mathrm{IC}_{50}$ values in the range of $27.72 \pm 3.71 \mu \mathrm{M}$ (Juglanin $\mathrm{H}$ ) to 
$383.54 \pm 29.57 \mu \mathrm{M}$ (Juglanin $\mathrm{J})$.

Regarding the anti-proliferative potential of the green husks from $J$. regia, Carvalho et al. (2010) reported IC $_{50}$ values of $285 \pm 51 \mu \mathrm{g} / \mathrm{mL}$ and $496 \pm 71 \mu \mathrm{g} / \mathrm{mL}$ for A-498 and 769-P (human kidney carcinomas) cell lines, respectively. For the Caco-2 (colorectal carcinoma) cells, the $\mathrm{IC}_{50}$ was higher than $500 \mu \mathrm{g} / \mathrm{mL}$. The increase on the TUNEL-positive apoptotic cell count of different extracts (methanol, $n$-hexane and chloroform) from this $J$. regia by-product was assessed for PC-3 (human prostate cancer) cells by Alshatwi et al. (2012), and the $n$-hexane extract was the most active. Moreover, the recent findings of SotoMaldonado et al. (2019) showed the antiproliferative and cytotoxic potentials of ethanolic extracts against the HL-60 cells, in which the plant extract presented higher activity than pure juglone. Overall, walnut green husks have shown to be a rich natural source of bioactive compounds with anti-proliferative potential, either in terms of the final extract or of their pure components.

The antimicrobial properties of the hydroethanolic extract of walnut green husks were also studied. Five Gram-negative (Escherichia coli, Klebsiella pneumoniae, Morganella morganii, Proteus mirabilis, and Pseudomonas aeruginosa) and three Gram-positive (Enterococcus fecalis, Listeria monocytogenes, and methicillin-resistant Staphylococcus aureus) bacteria obtained from clinical isolates were used (Alves et al., 2014). The results of the antibacterial activity of the extract and positive controls are presented in Table 3.

Both type of bacteria were susceptible to the ethanolic extract, being the lowest MIC (higher anti-bacterial potential) obtained for the methicillin-resistant Staphylococcus aureus (MRSA) strain (MIC $=5 \mathrm{mg}$ / $\mathrm{mL})$. The double of inhibitory concentration $(10 \mathrm{mg} / \mathrm{mL})$ was found to be effective against one Gram-positive (L. monocytogenes) and one Gram-negative (E. coli) bacteria. However, under the experimental concentration range, the extract was not able to inhibit $P$. aeruginosa (MIC $>20 \mathrm{mg} / \mathrm{mL}$ ), being the remaining species susceptible to a concentration of $20 \mathrm{mg} / \mathrm{mL}$ (K. pneumoniae, M. morganii, P. mirabilis, and $E$. fecalis). In all cases, the minimum bactericidal concentration was higher than $20 \mathrm{mg} / \mathrm{mL}$.

The antibacterial potential of Portuguese walnut green husks was previously evaluated by Oliveira et al. (2008). The authors evaluated the decoction extracts of several $J$. regia cultivars against different Gram-negative and Gram-positive bacteria with positive inhibitions against $S$. aureus (MIC $=0.1 \mathrm{mg} / \mathrm{mL}$ ), Bacillus cereus (MIC $=0.1-1 \mathrm{mg}$ / $\mathrm{mL}$ ), Bacillus subtilis (MIC $=0.1-10 \mathrm{mg} / \mathrm{mL}$ ) and $P$. aeruginosa (MIC $=100 \mathrm{mg} / \mathrm{mL}$ ). Later, Keskin et al. (2012)evaluated the activity of aqueous extracts by the disk diffusion method, obtaining higher inhibition zones against Pseudomonas fluorescens $(15 \mathrm{~mm})$ and lower for $B$. subtilis and $P$. aeruginosa $(8 \mathrm{~mm})$. The water extracts, studied by Fernández-Agulló et al. (2013), have shown higher potential against $B$. cereus (MIC $=20 \mathrm{mg} / \mathrm{mL}$ ), but lower for the Gram-negative $P$. aeruginosa and $E$. coli (MIC $=100 \mathrm{mg} / \mathrm{mL}$ ). On the other hand, Sharma et al.
(2013) evaluated the antibacterial activity of walnut green husks extracts obtained by different solvents (ethanol, ethyl acetate and water). Generally, the ethanolic extract showed higher diameter of inhibition against the studied bacteria (E. coli, K. pneumoniae and $S$. aureus), while the ethyl acetate extract was most effective against $B$. subtilis. Finally, the results obtained by Zhang et al. (2014) for the chloroform fraction of Chinese samples showed the lowest MIC values against $E$. coli, $P$. aeruginosa, B. subtilis and $S$. aureus $(6.25,1.56,3.13$ and $3.13 \mathrm{mg} / \mathrm{mL}$, respectively). In general, the MIC values obtained in the present work were higher in comparison with those reported in literature. These differences can be caused by several factors, such as the extraction methodology and solvents applied, and other factors related to the plant material, as previously discussed. Moreover, the selected microorganisms can also be a determinant factor, because the strains used in this work are multi-resistant clinical isolates, which may demand higher extract concentrations to inhibit their growth.

\section{Conclusions}

Walnut green husks presented a diverse phytochemical profile with different classes of phenolic compounds and naphthalene derivatives, including tetralone derivatives. The extract was richer in tetralone derivatives ( $14.2 \pm 0.2 \mathrm{mg} / \mathrm{g}$ ) compared to the other bioactive phytochemicals such as phenolic acids and flavonoids $(3.72 \pm 0.03 \mathrm{mg} / \mathrm{g})$. The hydroethanolic extract presented relevant antioxidant, anti-inflammatory, cytotoxic and antibacterial potentials, being all these assays carried out using in vitro cell models. In this regard, the antiproliferative potential of walnut green husks hydroethanolic extract was assessed for the first time for the selected cell cultures (MCF-7, NCI-H460, HeLa, HepG2 and PLP2). Moreover, it was also the first time that the anti-inflammatory properties of the extract were studied using a specific cell model (RAW264.7). Thus, this study contributes to increase the knowledge about $J$. regia walnut green husks since, as far as we know, it was the first time that this set of combined results are presented, showing in general consistent results with the few studies available in literature.

\section{CRediT authorship contribution statement}

Vanessa Vieira: Conceptualization, Methodology, Investigation, Formal analysis, Writing - original draft. Carla Pereira: Methodology, Investigation, Formal analysis. Rui M.V. Abreu: Methodology. Ricardo C. Calhelha: Methodology, Formal analysis. Maria José Alves: Methodology. Joảo A.P. Coutinho: Writing - review \& editing. Olga Ferreira: Writing - original draft, Writing - review \& editing, Funding acquisition. Lillian Barros: Methodology, Investigation, Formal analysis, Project administration, Writing - original draft, Writing - review \& editing. Isabel C.F.R. Ferreira: Conceptualization, Formal analysis,

Table 3

Antibacterial properties of J. regia green husks against Gram-positive and Gram-negative bacteria (mean, $\mathrm{n}=6$ ).

\begin{tabular}{|c|c|c|c|c|c|c|c|c|}
\hline & \multicolumn{2}{|c|}{ Ethanolic extract } & \multicolumn{2}{|c|}{ Ampicillin } & \multicolumn{2}{|l|}{ Imipenem } & \multicolumn{2}{|c|}{ Vancomycin } \\
\hline & MIC & MBC & MIC & $\mathrm{MBC}$ & MIC & MBC & MIC & $\mathrm{MBC}$ \\
\hline \multicolumn{9}{|l|}{ Gram-negative bacteria } \\
\hline Escherichia coli & 10 & $>20$ & $<0.15$ & $<0.15$ & $<0.0078$ & $<0.0078$ & n.t. & n.t. \\
\hline Klebsiella pneumoniae & 20 & $>20$ & 10 & 20 & $<0.0078$ & $<0.0078$ & n.t. & n.t. \\
\hline Morganella morganii & 20 & $>20$ & 20 & $>20$ & $<0.0078$ & $<0.0078$ & n.t. & n.t. \\
\hline Proteus mirabilis & 20 & $>20$ & $<015$ & $<0.15$ & $<0.0078$ & $<0.0078$ & n.t. & n.t. \\
\hline Pseudomonas aeruginosa & $>20$ & $>20$ & $>20$ & $>20$ & 0.5 & 1 & n.t. & n.t. \\
\hline \multicolumn{9}{|l|}{ Gram-positive bacteria } \\
\hline Enterococcus faecalis & 20 & $>20$ & $<0.15$ & $<0.15$ & n.t. & n.t. & $<0.0078$ & $<0.0078$ \\
\hline Listeria monocytogenes & 10 & $>20$ & $<0.15$ & $<0.15$ & $<0.0078$ & $<0.0078$ & n.t. & n.t. \\
\hline Methicillin-resistant Staphylococcus aureus (MRSA) & 5 & $>20$ & $<0.15$ & $<0.15$ & n.t. & n.t. & 0.25 & 0.5 \\
\hline
\end{tabular}

n.t. not tested. 
Funding acquisition, Project administration, Writing - review \& editing.

\section{Declaration of competing interest}

The authors declare that they have no known competing financial interests or personal relationships that could have appeared to influence the work reported in this paper.

\section{Acknowledgements}

The authors thank the Foundation for Science and Technology (FCT, Portugal) and FEDER under Programme PT2020 for financial support to CIMO (UID/AGR/00690/2019) and V. Vieira grant (SFRH/BD/ $108487 / 2015)$; national funding by FCT, P.I., through the institutional scientific employment program-contract for L. Barros and R. Calhelha contracts, and C. Pereira contract celebrated though the program-contract foreseen in No. 4, 5 and 6 of article $23^{\circ}$ of Decree-Law No. 57/ 2016, of 29th August, amended by Law No. 57/2017, of 19th July. To UID/CTM/50011/2019 (CICECO), financed by national funds through the FCT/MCTES. To POCI-01-0145-FEDER-006984 (LA LSRE-LCM), funded by ERDF, through POCI-COMPETE2020 and FCT. To project AllNat - POCI-01-0145-FEDER-030463 (PTDC/EQU-EPQ/30463/ 2017), funded by FEDER funds through COMPETE2020 - Programa Operacional Competitividade e Internacionalização (POCI), and by national funds through Foundation for Science and Technology (FCT/ MCTES), and to FEDER-Interreg España-Portugal programme for financial support through the project 0377_Iberphenol_6_E.

\section{References}

Abreu, R.M.V., Ferreira, I.C.F.R., Calhelha, R.C., Lima, R.T., Vasconcelos, M.H., Adega, F., Chaves, R., Queiroz, M.J.R.P., 2011. Anti-hepatocellular carcinoma activity using human HepG2 cells and hepatotoxicity of 6-substituted methyl 3-aminothieno[3,2-b] pyridine-2-carboxylate derivatives: in vitro evaluation, cell cycle analysis and QSAR studies. Eur. J. Med. Chem. 46, 5800-5806.

Akbari, V., Jamei, R., Heidari, R., Esfahlan, A.J., 2012. Antiradical activity of different parts of Walnut (Juglans regia L.) fruit as a function of genotype. Food Chem. 135, 2404-2410.

Alshatwi, A.A., Hasan, T.N., Shafi, G., Syed, N.A., Al-Assaf, A.H., Alamri, M.S., Al-Khalifa, A.S., 2012. Validation of the antiproliferative effects of organic extracts from the green husk of Juglans regia L. on PC-3 human prostate cancer cells by assessment of apoptosis-related genes. Evid. base Compl. Alternative Med. https://doi.org/10. $1155 / 2012 / 103026$

Alves, M., Ferreira, I., Lourenço, I., Costa, E., Martins, A., Pintado, M., 2014. Wild mushroom extracts as inhibitors of bacterial biofilm formation. Pathogens 3 , 667-679.

Bagheri, S., Ahmadvand, H., Khosrowbeygi, A., 2012. Various antioxidative activities of Iranian walnut (Juglans regia L.) green husks hydroalcoholic extract and its effects on LDL oxidation. J. Biol. Act. Prod. from Nat. 6, 330-340.

Balasundram, N., Sundram, K., Samman, S., 2006. Phenolic compounds in plants and agri-industrial by-products: antioxidant activity, occurrence, and potential uses. Food Chem. 99, 191-203.

Barreira, J.C.M., Rodrigues, S., Carvalho, A.M., Ferreira, I.C.F.R., 2013. Development of hydrosoluble gels with Crataegus monogyna extracts for topical application: evaluation of antioxidant activity of the final formulations. Ind. Crop. Prod. 42, 175-180.

Barros, L., Pereira, E., Calhelha, R.C., Dueñas, M., Carvalho, A.M., Santos-Buelga, C., Ferreira, I.C.F.R., 2013. Bioactivity and chemical characterization in hydrophilic and lipophilic compounds of Chenopodium ambrosioides L. J. Funct. Foods 5, $1732-1740$.

Beiki, T., Najafpour, G.D., Hosseini, M., 2018. Evaluation of antimicrobial and dyeing properties of walnut (Juglans regia L.) green husk extract for cosmetics. Color. Technol. 134, 71-81.

Bessada, S.M.F., Barreira, J.C.M., Barros, L., Ferreira, I.C.F.R., Oliveira, M.B.P.P., 2016 Phenolic profile and antioxidant activity of Coleostephus myconis (L.) Rchb.f.: an underexploited and highly disseminated species. Ind. Crop. Prod. 89, 45-51.

Butler, M.S., Robertson, A.A.B., Cooper, M.A., 2014. Natural product and natural product derived drugs in clinical trials. Nat. Prod. Rep. 31, 1612-1661.

Carocho, M., Ferreira, I.C.F.R., 2013. A review on antioxidants, prooxidants and related controversy: natural and synthetic compounds, screening and analysis methodologies and future perspectives. Food Chem. Toxicol. 51, 15-25.

Carvalho, M., Ferreira, P.J., Mendes, V.S., Silva, R., Pereira, J.A., Jerónimo, C., Silva, B.M., 2010. Human cancer cell antiproliferative and antioxidant activities of Juglans regia L. Food Chem. Toxicol. 48, 441-447.

Chatrabnous, N., Yazdani, N., Tavallali, V., Vahdati, K., 2018. Preserving quality of fresh walnuts using plant extracts. LWT - Food Sci. Technol. (Lebensmittel-Wissenschaft -Technol.) 91, 1-7.
Clifford, M.N., Johnston, K.L., Knight, S., Kuhnert, N., 2003. Hierarchical scheme for LCMSn identification of chlorogenic acids. J. Agric. Food Chem. 51, 2900-2911.

Clifford, M.N., Knight, S., Kuhnert, N., 2005. Discriminating between the six isomers of dicaffeoylquinic acid by LC-MSn. J. Agric. Food Chem. 53, 3821-3832.

Corrêa, R.C.G., De Souza, A.H.P., Calhelha, R.C., Barros, L., Glamoclija, J., Sokovic, M., Peralta, R.M., Bracht, A., Ferreira, I.C.F.R., 2015. Bioactive formulations prepared from fruiting bodies and submerged culture mycelia of the Brazilian edible mushroom Pleurotus ostreatoroseus Singer. Food Funct. 6, 2155-2164.

Cosmulescu, S., Botu, M., Achim, G., Baciu, A., Gruia, M., Trandafir, I., 2014a. Polyphenol content in walnut (Juglans regia L.) mature leaves. Acta Hortic. 1050, 205-212.

Cosmulescu, S., Trandafir, I., Achim, G., Baciu, A., 2011. Juglone content in leaf and green husk of five walnut (Juglans regia L.) cultivars. Not. Bot. Horti Agrobot. ClujNapoca 39, 237-240.

Cosmulescu, S., Trandafir, I., Achim, G., Botu, M., Baciu, A., Gruia, M., 2010. Phenolics of green husk in mature walnut fruits. Not. Bot. Horti Agrobot. Cluj-Napoca 38, 53-56.

Cosmulescu, S., Trandafir, I., Nour, V., 2014b. Seasonal variation of the main individual phenolics and juglone in walnut (Juglans regia) leaves. Pharm. Biol. 52, 575-580.

Crozier, A., Jaganath, I.B., Clifford, M.N., 2006. Phenols, polyphenols and tannins: an overview. In: Crozier, A., Clifford, M.N., Ashihara, H. (Eds.), Plant Secondary Metabolites: Occurrence, Structure and Role in the Human Diet. Blackwell Publishing Ltd, Oxford, pp. 1-24.

Du, H., Li, C., Wen, Y., Tu, Y., Zhong, Y., Yuan, Z., Li, Y., Liang, B., 2014. Secondary metabolites from pericarp of Juglans regia. Biochem. Systemat. Ecol. 54, 88-91.

Fernández-Agulló, A., Pereira, E., Freire, M.S., Valentão, P., Andrade, P.B., GonzálezÁlvarez, J., Pereira, J.A., 2013. Influence of solvent on the antioxidant and antimicrobial properties of walnut (Juglans regia L.) green husk extracts. Ind. Crop. Prod. 42, 126-132.

Gawlik-Dziki, U., Durak, A., Pecio, L., Kowalska, I., 2014. Nutraceutical potential of tinctures from fruits, green husks, and leaves of Juglans regia L. Sci. World J. https:// doi.org/10.1155/2014/501392.

Ghasemi, K., Ghasemi, Y., Ehteshamnia, A., Nabavi, S.M., Nabavi, S.F., Ebrahimzadeh, M.A., Pourmorad, F., 2011. Influence of environmental factors on antioxidant activity, phenol and flavonoids contents of walnut (Juglans regia L .) green husks. J. Med. Plants Res. 5, 1128-1133.

Gupta, D., 2015. Methods for determination of antioxidant capacity: a review. Int. J. Pharma Sci. Res. 6, 546-566.

Izadiyan, Z., Shameli, K., Hara, H., Mohd Taib, S.H., 2018. Cytotoxicity assay of biosynthesis gold nanoparticles mediated by walnut (Juglans regia) green husk extract. J. Mol. Struct. 1151, 97-105.

Jahanban-Esfahlan, A., Ostadrahimi, A., Tabibiazar, M., Amarowicz, R., 2019. A comparative review on the extraction, antioxidant content and antioxidant potential of different parts of walnut (Juglans regia L.) fruit and tree. Molecules 24, 2133.

Jin-Hai, H., Xiao-Wei, D., Guo-Dong, S., Wen-Ting, D., Wei-Ming, W., 2018. Identification and characterization of major constituents in Juglans mandshurica using ultra performance liquid chromatography coupled with time-of-flight mass spectrometry (UPLC-ESI-Q-TOF/MS). Chin. J. Nat. Med. 16, 525-545.

Keskin, D., Ceyhan, N., Ugur, A., 2012. Chemical composition and in vitro antimicrobial activity of walnut (Juglans regia) green husks and leaves from West Anatolia. J. Pure Appl. Microbiol. 6, 583-588.

Kuete, V., Kamga, J., Sandjo, L.P., Ngameni, B., Poumale, H.M.P., Ambassa, P., Ngadjui, B.T., 2011. Antimicrobial activities of the methanol extract and compounds from Artocarpus communis (Moraceae). BMC Compl. Alternative Med. 11, 1-6.

Li, C.-Y., Du, H.-J., Su, X.-H., Zhong, Y.-J., Yuan, Z.-P., Li, Y.-F., Liang, B., 2013. Juglanones A and B: two novel tetralone dimers from walnut pericarp (Juglans regia). Helv. Chim. Acta 96, 1031-1035.

Li, C., Liu, J.-X., Zhao, L., Di, D.-L., Meng, M., Jiang, S.-X., 2008a. Capillary zone elec trophoresis for separation and analysis of four diarylheptanoids and an $\alpha$-tetralone derivative in the green walnut husks (Juglans regia L.). J. Pharmaceut. Biomed. Anal. 48, 749-753.

Li, Y., Ruan, H., Zhou, X., Zhang, Y., Pi, H., Wu, J., 2008b. Cytotoxic diarylheptanoids from pericarps of Juglans cathayensis Dode. Chem. Res. Chin. Univ. 24, 427-429.

Liu, J., Meng, M., Li, C., Huang, X., Di, D., 2008. Simultaneous determination of three diarylheptanoids and an $\alpha$-tetralone derivative in the green walnut husks (Juglans regia L.) by high-performance liquid chromatography with photodiode array detector. J. Chromatogr. A 1190, 80-85.

Liu, Q., Zhao, P., Li, X.-C., Jacob, M.R., Yang, C.-R., Zhang, Y.-J., 2010. New $\alpha$-tetralone galloylglucosides from the fresh pericarps of Juglans sigillata. Helv. Chim. Acta 93, 265-271.

Lockowandt, L., Pinela, J., Lobo, C., Pereira, C., Abreu, R.M.V., Calhelha, R.C., José, M., Barros, L., Bredol, M., Ferreira, I.C.F.R., 2019. Chemical features and bioactivities of cornflower (Centaurea cyanus L.) capitula: the blue flowers and the unexplored nonedible part. Ind. Crop. Prod. 128, 496-503.

Martínez, M.L., Labuckas, D.O., Lamarque, A.L., Maestri, D.M., 2010. Walnut (Juglans regia L.): genetic resources, chemistry, by-products. J. Sci. Food Agric. 90, 1959-1967.

Meshkini, A., Tahmasbi, M., 2017. Antiplatelet aggregation activity of walnut hull extract via suppression of reactive oxygen species generation and caspase activation. J. Acupunct. Meridian Stud. 10, 193-203.

Newman, D.J., Cragg, G.M., 2016. Natural products as sources of new drugs from 1981 to 2014. J. Nat. Prod. 79, 629-661.

Oliveira, I., Sousa, A., Ferreira, I.C.F.R., Bento, A., Estevinho, L., Pereira, J.A., 2008. Total phenols, antioxidant potential and antimicrobial activity of walnut (Juglans regia L.) green husks. Food Chem. Toxicol. 46, 2326-2331.

Pereira, J.A., Oliveira, I., Sousa, A., Valentão, P., Andrade, P.B., Ferreira, I.C.F.R., Ferreres, F., Bento, A., Seabra, R., Estevinho, L., 2007. Walnut (Juglans regia L.) leaves: phenolic compounds, antibacterial activity and antioxidant potential of 
different cultivars. Food Chem. Toxicol. 45, 2287-2295.

Pinela, J., Prieto, M.A., Pereira, E., Jabeur, I., Filomena, M., Barros, L., Ferreira, I.C.F.R., 2019. Optimization of heat- and ultrasound-assisted extraction of anthocyanins from Hibiscus sabdariffa calyces for natural food colorants. Food Chem. 275, 309-321.

Pires, T.C.S.P., Dias, M.I., Barros, L., Alves, M.J., Oliveira, M.B.P.P., Santos-Buelga, C., Ferreira, I.C.F.R., 2018. Antioxidant and antimicrobial properties of dried Portuguese apple variety (Malus domestica Borkh. cv Bravo de Esmolfe). Food Chem. 240, 701-706.

Rostagno, M.A., Prado, J.M., 2013. Natural Product Extraction - Principles and Applications, first ed. The Royal Society of Green Chemistry, Cambridge.

Salejda, A.M., Janiewicz, U., Korzeniowska, M., Kolniak-Ostek, J., Krasnowska, G., 2016. Effect of walnut green husk addition on some quality properties of cooked sausages. LWT - Food Sci. Technol. (Lebensmittel-Wissenschaft -Technol.) 65, 751-757.

Sampaio, B.L., Edrada-Ebel, R., Da Costa, F.B., 2016. Effect of the environment on the secondary metabolic profile of Tithonia diversifolia: a model for environmental metabolomics of plants. Sci. Rep. 6, 1-11.

Santos, A., Barros, L., Calhelha, R.C., Dueñas, M., Carvalho, A.M., Santos-Buelga, C., Ferreira, I.C.F.R., 2013. Leaves and decoction of Juglans regia L.: different performances regarding bioactive compounds and in vitro antioxidant and antitumor effects. Ind. Crop. Prod. 51, 430-436.

Sharma, P., Ravikumar, G., Kalaiselvi, M., Gomathi, D., Uma, C., 2013. In vitro antibacterial and free radical scavenging activity of green hull of Juglans regia. J. Pharm. Anal. 3, 298-302.

Soto-Maldonado, C., Vergara-Castro, M., Jara-Quezada, J., Caballero-Valdés, E., MüllerPavez, A., Zúñiga-Hansen, M.E., Altamirano, C., 2019. Polyphenolic extracts of walnut (Juglans regia) green husk containing juglone inhibit the growth of HL-60 cells and induce apoptosis. Electron. J. Biotechnol. 39, 1-7.

Stampar, F., Solar, A., Hudina, M., Veberic, R., Colaric, M., 2006. Traditional walnut liqueur - cocktail of phenolics. Food Chem. 95, 627-631.

Sun, J.-X., Zhao, X.-Y., Fu, X.-F., Yu, H.-Y., Li, X., Li, S.-M., Ruan, H.-L., 2012. Three new naphthalenyl glycosides from the root bark of Juglans cathayensis. Chem. Pharm. Bull. 60, 785-789.

Talapatra, S.K., Karmacharya, B., De, S.C., Talapatra, B., 1988. (-)-Regiolone, an $\alpha$-tetralone from Juglans regia: structure, stereochemistry and conformation. Phytochemistry 27, 3929-3932.

Tripathi, P., Tripathi, P., Kashyap, L., Singh, V., 2007. The role of nitric oxide in inflammatory reactions. FEMS Immunol. Med. Microbiol. 51, 443-452.

Wang, T.-M., Fu, Y., Yu, W.-J., Chen, C., Di, X., Zhang, H., Zhai, Y.-J., Chu, Z.-Y., Kang, T.G., Chen, H.-B., 2017. Identification of polar constituents in the decoction of Juglans mandshurica and in the medicated egg prepared with the decoction by HPLC-Q-TOF MS2. Molecules 22, 1-16.

Yang, H., Ma, Y., Gao, C., Wang, B., ARuhan, Lin, C., Feng, H., Wang, L., Huang, J., Wang, J., 2019. Five novel diarylheptanoids from green walnut husks (Juglans regia L.). Fitoterapia 134, 221-225.

Zhang, Q.W., Lin, L.G., Ye, W.C., 2018. Techniques for extraction and isolation of natural products: a comprehensive review. Chin. Med. 13, 1-26.

Zhang, W., He, K., Pu, Q., 2014. Antimicrobial and antioxidant activities of extracts from walnut green husks. Chin. J. Appl. Environ. Biol. 20, 87-92.

Zhou, Y., Yang, B., Jiang, Y., Liu, Z., Liu, Y., Wang, X., Kuang, H., 2015. Studies on cytotoxic activity against HepG-2 Cells of naphthoquinones from green walnut husks of Juglans mandshurica Maxim. Molecules 20, 15572-15588. 